\title{
Clinical Effects of the Recombinant Feline Interferon- $\omega$ on Experimental Parvovirus Infection in Beagle Dogs
}

\author{
Kenji ISHIWATA, Tomonori MINAGAWA and Tsunesuke KAJIMOTO1) \\ Department of Microbiology, School of Medicine, Hokkaido University, Sapporo 060-8638 and "'Animal Health Products Development, \\ Chemicals Business Development Department, Toray Industries, Inc., Tokyo 103-8666, Japan
}

(Received 4 December 1997/Accepted 22 April 1998)

\begin{tabular}{l} 
ABSTRACT. The clinical effects of recombinant feline interferon- $\omega$ (rFeIFN- $\omega)$, produced in silkworm by recombinant baculovirus, were \\
examined in $3-4$ month-old beagle dogs given an experimental canine parvovirus type-2 (CPV-2) infection. Clinical symptoms, such as \\
pyrexia, vomiting, anorexia and diarrhea, were observed on day 4 after oral inoculation of $10^{7} \mathrm{TCID}_{50}$ of CPV-2 (cc 238 strain) in almost \\
all the inoculated dogs. From day 4 , rFeIFN- $\omega(1$ mega units/kg/day) or physiological saline was administered intravenously to infected \\
dogs for 3 consecutive days. Seven out of 17 dogs treated with physiological saline showed hemorrhagic diarrhea and continuously \\
expressed severe clinical enteritis; one dog died with a large amount of hemorrhagic rice-water stool on day 6 after viral exposure. In \\
contrast, 4 out of 12 dogs treated with rFeIFN- $\omega$ showed severe clinical enteritis associated with intermittent diarrhea. Scoring of fecal \\
condition revealed that treatment with rFeIFN- $\omega$ significantly shifted the enteritis from a severe to mild form. Furthermore, rFeIFN- $\omega$ \\
administered in the morning decreased the number of dogs expressing clinical enteritis in the evening suggesting a rapid effect. Vomiting \\
and anorexia were also improved by treatment with rFeIFN- $\omega$. These results suggest that rFeIFN- $\omega$ can reduce severe enteritis caused by \\
CPV-2 infection in dogs. - KEY wORDs: beagle dog, canine parvovirus, enteritis, experimental infection, recombinant feline interferon- $\omega$. \\
\hline
\end{tabular}

Outbreaks of canine parvovirus type-2 (CPV-2) infection are characterized by high morbidity and mortality, and have spread rapidly worldwide since 1978 [11, 23]. The appearance of new subtype of this virus generally present less severe disease in dogs that have a better survival rate $[24,26]$. However, puppies born in breeding populations have greater risk of infections that are often fatal [5]. Adult dogs kept outdoors often manifest clinically severe symptoms, especially those dogs with an accompanying parasitic infection. Although modified live vaccines are now available, treatment for this disease is still symptomatic and based simply on principles of good supportive care [3, 26]. This infection, when accompanied by severe gastroenteritis, is one of the most important diseases of dogs.

It is now clear that interferons (IFNs), identified firstly by Nagano and Kojima [21] and later named by Isaacs and Lindenmann [9], can modulate a number of cellular and immune functions, as well as affect virus replication [28]. The potent antiviral and antitumor activity of IFNs has been used therapeutically in humans [8], and tried in cattle [12], horses [16], and pigs [13]. Recombinant feline interferon- $\omega$ $(\mathrm{rFeIFN}-\omega)$, produced in silkworm larvae using a baculovirus vector [27, 33], has shown antiviral activity against infection with feline calicivirus, herpesvirus and enteropathogenic virus [19, 35]. Further, Tateyama et al. [30] demonstrated growth inhibitory activity of rFeIFN- $\omega$ on canine tumor-cell lines, even though IFNs express a relatively high degree of species specificity. In the present study, we examined the clinical effects of rFeIFN- $\omega$ on CPV-2 infection in beagle dogs.

\section{MATERIALS AND METHODS}

Experimental animals: Specific pathogen free beagle dogs (NRD strain) 3 to 4 months of age were obtained from Hokudoh Co., Ltd., Hokkaido, Japan and housed in individual cages during the course of the experiments. These dogs had no antibody to CPV-2 (titer $\leq 1: 4$ ) just before viral inoculation. At the end of experiments, all dogs were sacrificed under anesthesia according to the guideline for Animal Experiments, Hokkaido University, School of Medicine.

Virus: Canine parvovirus (CPV; cc 238 strain) was used. The strain was originally isolated in Okayama Prefecture, Japan in 1991, from the feces of a dog with vomiting, diarrhea and hemorrhagic stool. The strain was established in Crandell feline kidney (CRFK; ATCC CCL 94) cell cultures at the Tsukuba Central Laboratories, Kyoritsu Shoji Company, Ibaraki, Japan. The virus is identified as a type CPV-2a by its reactivity to specific monoclonal antibodies. Virus suspensions containing $10^{7} \mathrm{TCID}_{50}$ were inoculated orally. The dogs were diagnosed with CPV-2 infection based on the presence of clinical signs, and the infection was confirmed by seroconversion and detection of viral DNA in rectal feces by a PCR method.

Clinical observations and score of clinical symptoms: Rectal temperatures, vomiting, appetite and fecal condition were recorded daily for 2 weeks, and twice daily in the morning and in the evening from day 3 to 10 after virus inoculation. Rectal temperature of over $39.5^{\circ} \mathrm{C}$ was expressed as pyrexia. The degree of vomiting, appetite and fecal condition were expressed by scores shown in Table 1. For scoring the clinical symptoms, the degree of symptom 
Table 1. Score of clinical symptoms

\begin{tabular}{cccc}
\hline Point & Vomit condition $^{\text {a) }}$ & Appetite $^{\text {b) }}$ & Fecal condition $^{\mathrm{c})}$ \\
\hline 0 & No vomiting & $0 \%$ (eat all) & Solid (normal) \\
1 & Foamy vomit with saliva & & Soft \\
2 & Foamy vomit with gastric juice & $25 \%$ remained & Diarrhea \\
4 & Gastricus contents & $50 \%$ remained & Mucous diarrhea \\
5 & & $75 \%$ remained & $\begin{array}{c}\text { Watery diarrhea } \\
6\end{array}$ \\
7 & & Mucous diarrhea with blood \\
8 & Abundant gastricus contents & $100 \%$ remained & Watery diarrhea with blood \\
\hline
\end{tabular}

a) In case of plural vomits, each vomit was counted, b) Dogs were fed after every morningobservation and appetite was estimated at the afternoon-observation according to the amount of feed remaining, c) In case of plural fecal conditions, each sample was counted according to its volume.

was measured by the incidence and excreted volume of vomits or feces. Canine parvovirus infection often expresses a rapid exacerbation of clinical symptoms and the synergistic effect of confounding conditions can result in fatalities. Therefore, in the case of plural vomits or feces, each occurrence was scored and the total score summed. For vomiting, the total score of the morning and the evening was represented. For feces, the volume and condition of the feces was scored and represented in each observation as follows: the same volume of feces with a different condition was scored as the sum of half of each assigned point value; in the case of different volumes of various conditions of feces, the sum of the assigned value of the largest volume of feces and $1 / 4$ point of the smallest volume were represented. Soft feces does not always imply disease, but diarrhea is clinically important so that each assigned value was set at 1 for the former and at 4 for the latter. Intermediate levels of feces between soft and diarrhea were assigned a value of 2.5. In this scoring system, the score of soft feces or of a minute volume of diarrhea would not exceed 2.0. Dogs marked $>2.0$ in score of fecal condition represented clinical enteritis in this study. For appetite, dogs were fed after morning observations and the amount remaining at the evening observations was scored.

Detection of $C P V-2$ in fecal samples by PCR assay: Capsid genes of CPV-2 from rectal swabs were checked by a PCR method [20]. Genes encoding the capsid proteins VP1 and VP2 were amplified by using a GeneAmp PCR Reagent Kit with AmpliTaq DNA Polymerase (Perkin-Elmer Cetus, Norwalk, Connecticut) and a set of 19-mer primers VPF and VPR: VPF, 5'-ATGGCACCTCCGGCAAAGA3', and VPR, 5'-TTTCTAGGTGCTAGTTGAG-3'. Ten microliters of the reaction product was analyzed electrophoretically in $1 \%$ (wt/vol) agarose gel with TrisBoric acid-EDTA buffer ( $\mathrm{pH}$ 8.2). The bands were visualized after staining with ethidium bromide.

Serum neutralization test: Serum neutralization titer against CPV was measured by a micro-neutralization test. Serum was serially diluted with Eagle's minimal essential medium containing $10 \%$ fetal calf serum in wells of a $96-$ well flat-bottom plate. Virus prediluted to a titer of 100
$\mathrm{TCID}_{50} / 25 \mu l$ was then added to each well in a $25 \mu l$ amount. The plate was gently agitated for mixing and was incubated at $37^{\circ} \mathrm{C}$ for $1 \mathrm{hr}$. Then $3 \times 10^{4} \mathrm{CRFK}$ cells were added to each well and the plate was incubated in the chamber. After $24 \mathrm{hr}$ incubation, medium was replaced and the plate was further incubated for 7 days. Supernatants from each well were harvested and examined for CPV-specific hemagglutinins [20]. Formalin-fixed pig erythrocytes were used for the test. The titer was defined as the reciprocal of the highest serum dilution at which no hemagglutinin was detected.

$r F e I F N-\omega$ administration: $\mathrm{rFeIFN}-\omega$ was supplied from Toray Industries, Inc., Tokyo, Japan. Ten mega units (MU)/ vial were resuspended in with $1 \mathrm{~m} l$ of physiological saline and immediately injected intravenously as $1 \mathrm{MU} / \mathrm{kg}$. rFeIFN- $\omega$ was administered once a day for 3 successive days from day 4 after virus inoculation in the morning after routine observation of animal condition. Day 4 after virus inoculation was the time when all of the infected animals showed clinical signs of the infection. Control infectedanimals received physiological saline instead of rFeIFN- $\omega$.

Experimental design: Three experiments were conducted. In the first one, the course of infection of $5 \mathrm{dogs}$ given CPV-2 (cc 238 strain) was observed. In the second experiment, $8 \mathrm{dogs}$ were divided into 2 groups of 4 that received either $\mathrm{rFeIFN}-\omega$ or physiological saline. In the third experiment, two groups of $8 \mathrm{dogs}$ were treated similarly to those in the second experiment. Blood samples for serology were collected prior to and at day 14 after virus inoculation. Fresh fecal specimens from the rectum were collected for virus detection with swabs prior to CPV2 inoculation, and on days 3, 5, 7, 10 and 14 after virus inoculation.

Statistical analysis: Data were analyzed by the Student's $t$-test or $\chi^{2}$-test, and $P$-values of $<0.05$ were accepted as being significant.

\section{RESULTS}

General observations: In the first experiment, clinical signs of pyrexia (4/5), vomiting (4/5), anorexia (4/5) and 
Table 2. CPV-2 virus DNA detected from rectal swab extracts by a PCR methoda)

\begin{tabular}{|c|c|c|c|c|c|c|c|}
\hline \multirow[t]{2}{*}{ Exp.\# } & \multirow[t]{2}{*}{ Treatment } & \multicolumn{6}{|c|}{ Days after inoculation } \\
\hline & & 0 & 3 & 5 & 7 & 10 & 14 \\
\hline 1 & - & $0 / 5$ & $3 / 5$ & $1 / 5$ & $5 / 5$ & $0 / 5$ & $0 / 5$ \\
\hline \multirow[t]{2}{*}{2} & Saline & $0 / 4$ & $2 / 4$ & $3 / 4$ & $1 / 4$ & $0 / 4$ & $0 / 4$ \\
\hline & rFeIFN & $0 / 4$ & $3 / 4$ & $4 / 4$ & $0 / 4$ & $0 / 4$ & $0 / 4$ \\
\hline \multirow[t]{2}{*}{3} & Saline ${ }^{b)}$ & $0 / 8$ & $8 / 8$ & $8 / 8$ & $3 / 7$ & $1 / 7$ & $0 / 7$ \\
\hline & rFeIFN & $0 / 8$ & $7 / 8$ & $8 / 8$ & $5 / 8$ & $1 / 8$ & $0 / 8$ \\
\hline
\end{tabular}

a) Positive number of dogs/total number of dogs examined, b) $\mathrm{A}$ saline treated control dog died on day 6 after virus inoculation; CPV-

2 DNA was detected from the rectal swab of the carcass.

diarrhea $(5 / 5)$ were observed on the morning of day 4 after virus inoculation. Virus shedding into the feces was evident from day 3 and continued to day 7 after inoculation (Table 2). Seroconversion also confirmed the CPV-2 infection of all dogs. Neutralization antibody titers of all virus infectedanimals were elevated on day 14 after inoculation. Two dogs had titers $=1: 512$ and the remaining had titers $\geq$ $1: 1,024$. Clinical signs were disappeared until day 14 after virus inoculation in all dogs (data not shown).

In the second and third experiments, clinical signs also appeared on the morning of day 4 after exposure as was observed in the first experiment; $r F e I F N-\omega$ or physiological saline was administered from day 4 after inoculation for 3 successive days. Viral capsid gene was detected in feces from day 3 to day 7 after virus inoculation in the second experiment and until day 10 in the third experiment (Table 2). All dogs shed viral DNA and rFeIFN- $\omega$ treatment had no effect on virus shedding. The serum neutralization titers on day 14 were elevated in all animals (titer $\geq 1: 1,024$ 8,192 ). One control dog, in the third experiment died on the morning of day 6 ; it continuously expressed watery stool from the evening of day 3 and hemorrhagic rice-water stool on day 5 after virus inoculation. Because the pathogenic process observed in $\mathrm{dog}$ s from the control groups in experiments 2 and 3 were similar to that of the first experiment, data from all three experiments were pooled for further analysis.

Effect of rFeIFN- $\omega$ on pyrexia, vomiting and appetite: Pyrexia was observed around day 4 after virus inoculation in the control (14 out of 17) and the rFeIFN- $\omega$-treated (10 out of 12) groups (data not shown). In both groups, almost all the dogs recovered to the normal range on day 5-6 after virus inoculation. No significant differences were seen in the two groups by the Student's $t$-test.

As shown in Fig. 1, 12 out of 17 dogs in the control, and 8 out of 12 dogs in the rFeIFN- $\omega$-treated groups expressed vomiting on day 4 after virus inoculation. Vomiting was continuously or repeatedly observed in both groups and there was no significant differences between the two groups during the recovery phase of the disease. The percentage of dogs vomiting on the last day (6 day after virus inoculation) and the next day (7 day) of administration of rFeIFN- $\omega$ was $8.3 \%(1 / 12)$ and $16.7 \%(2 / 12)$, respectively, while that of control dogs was $23.5 \%(4 / 17)$ and $31.5 \%(5 / 16)$,

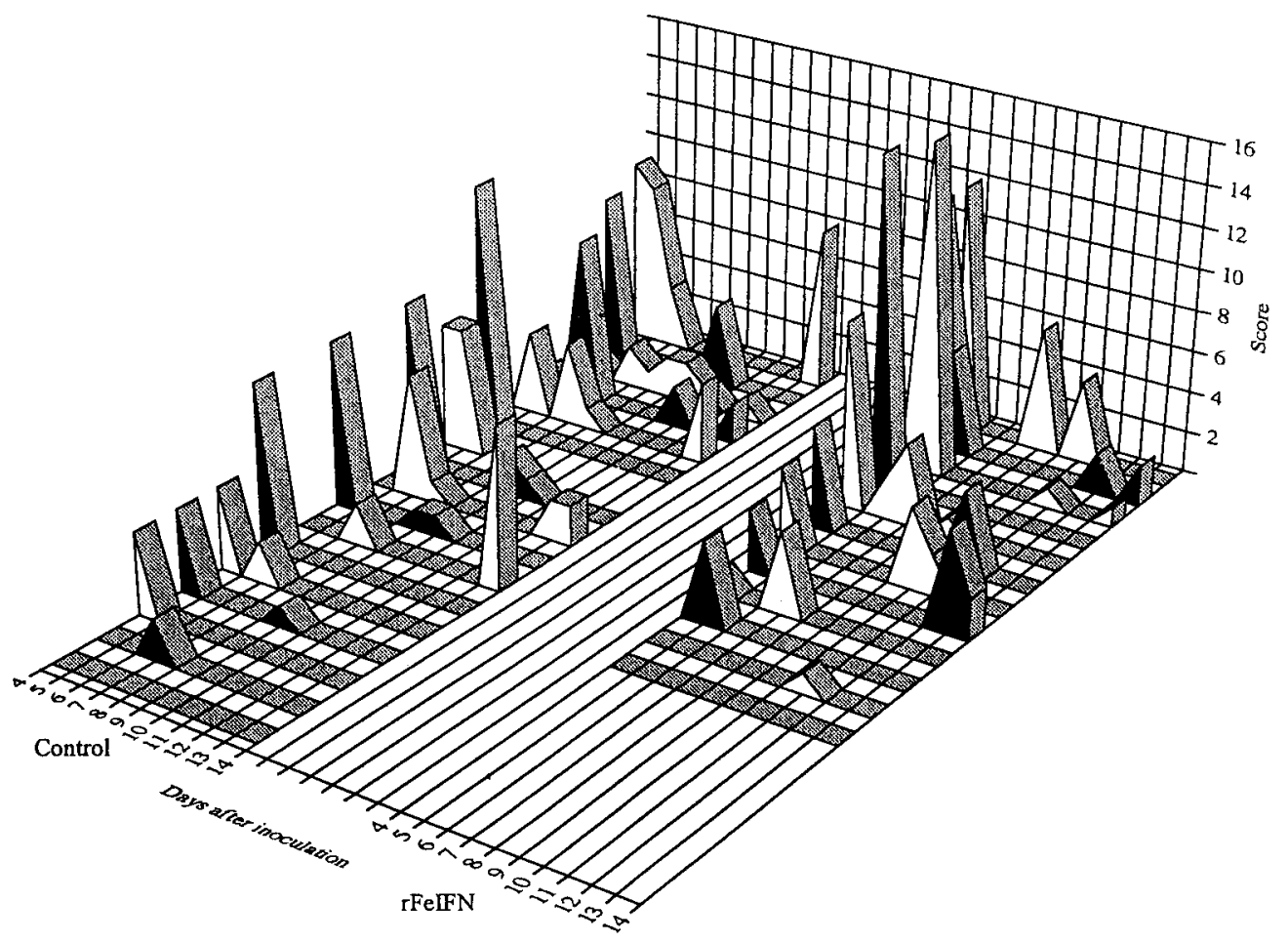

Fig. 1. Scores of vomiting of dogs experimentally infected with CPV-2 cc 238 strain. Vomit condition was scored according to Table 1 (see materials and methods in detail). 


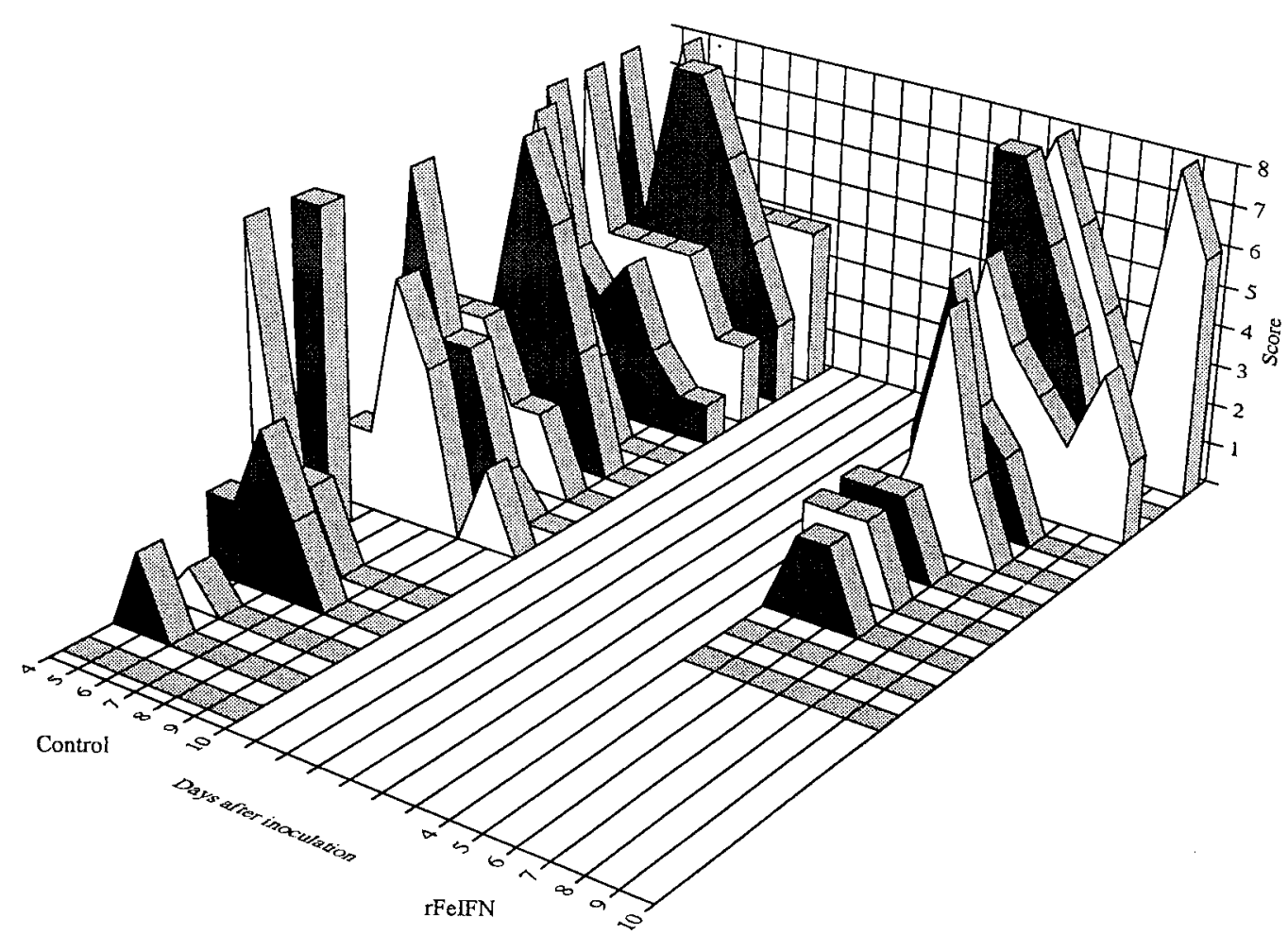

Fig. 2. Scores of appetite of dogs experimentally infected with CPV-2 cc 238 strain. Scores were marked according to Table 1 (see Materials and Methods in detail).

respectively. One dog treated with $\mathrm{rFeIFN}-\omega$ showed two pieces of abundant gastricus contents on the morning of day 5. This dog also showed pyrexia, anorexia $(75 \%$ of the food remained) and the same amounts of solid and hemorrhagic rice-water stool; severity of the infection peaked at this time.

Two dogs in each group showed anorexia to some degree from the beginning of the experiment, therefore, those dogs were excluded from the data analysis. Anorexia was observed in 16 out of 25 dogs (control; 10/15, rFeIFN- $\omega$ treated; 6/10) on day 4 after inoculation (Fig. 2). From 6 to 8 days after inoculation, the degree of anorexia was reduced in all dogs treated with rFeIFN- $\omega$, while in the control group, several dogs continuously showed severe anorexia; no significant differences were seen in the reduction or recovery from anorexia in the two groups.

Effect of rFeIFN- $\omega$ on fecal condition: On the morning of day 4, 21 out of $29 \mathrm{dogs}$, including 13 out of 17 in the control and 8 out of 12 in the rFeIFN- $\omega$-treated groups, expressed clinical enteritis (score $>2.0$ ). However, some dogs in each group did not show clinical enteritis until day 7 after virus inoculation (control $3 / 17$ and the rFeIFN- $\omega$ treated 3/12) (Fig. 3). The mean score in the morning of day 4 after virus inoculation was $2.7(\mathrm{SD}=1.9, \mathrm{n}=17)$ in the control and $2.8(\mathrm{SD}=2.1, \mathrm{n}=12)$ in the $\mathrm{rFeIFN}-\omega$-treated group. The mean score of clinical enteritis was $3.4(\mathrm{SD}=1.5$, $\mathrm{n}=13)$ in the control and $3.9(\mathrm{SD}=1.7, \mathrm{n}=8)$ in the rFeIFN$\omega$-treated group suggesting that there were no significant differences in the incidence and degree of clinical enteritis between the two groups at the beginning of treatment.

In the control group, scores $\geq 8.0$ appeared in $4 \mathrm{dogs}$ and 7 out of 17 dogs showed repeated high scores due to hemorrhagic stool. In contrast, no rFeIFN- $\omega$-treated dogs exhibited scores $\geq 8.0$ after $\mathrm{rFeIFN}-\omega$ administration and high scores, marked by 4 out of $12 \mathrm{dogs}$, were intermittent. On day 7 after virus inoculation, 4 out of 16 control dogs and 2 out of 12 rFeIFN- $\omega$-treated dogs showed clinical enteritis. There were no clinical differences in fecal condition between the two groups thereafter.

The sum of scores from the evening of day 4 to the evening of day 10 of individual dogs from each group was compared. The average score of dogs in the control group was significantly higher (average $\pm \mathrm{SD} ; 19.1 \pm 9.8, \mathrm{n}=17$ ) than that of dogs from the rFeIFN- $\omega$-treated group (11.9 \pm $8.4, \mathrm{n}=12$ ), suggesting that $\mathrm{rFeIFN}-\omega$ administrations shifted the severity of enteritis from severe to mild (Student's $t$ test; $P<0.05)$.

To estimate the onset of the treatment effect of the administration of $\mathrm{rFeIFN}-\omega$, the ratio of dogs expressing clinical enteritis in the morning was compared to those in the evening (Fig. 4). Treatment with rFeIFN- $\omega$ in the morning significantly reduced $\left(\chi^{2}\right.$-test, $\left.P=0.0104\right)$ the ratio of dogs with clinical enteritis in the evening on day 4 after virus inoculation and that tendency was observed on the evening of day $6(P=0.0513)$. 


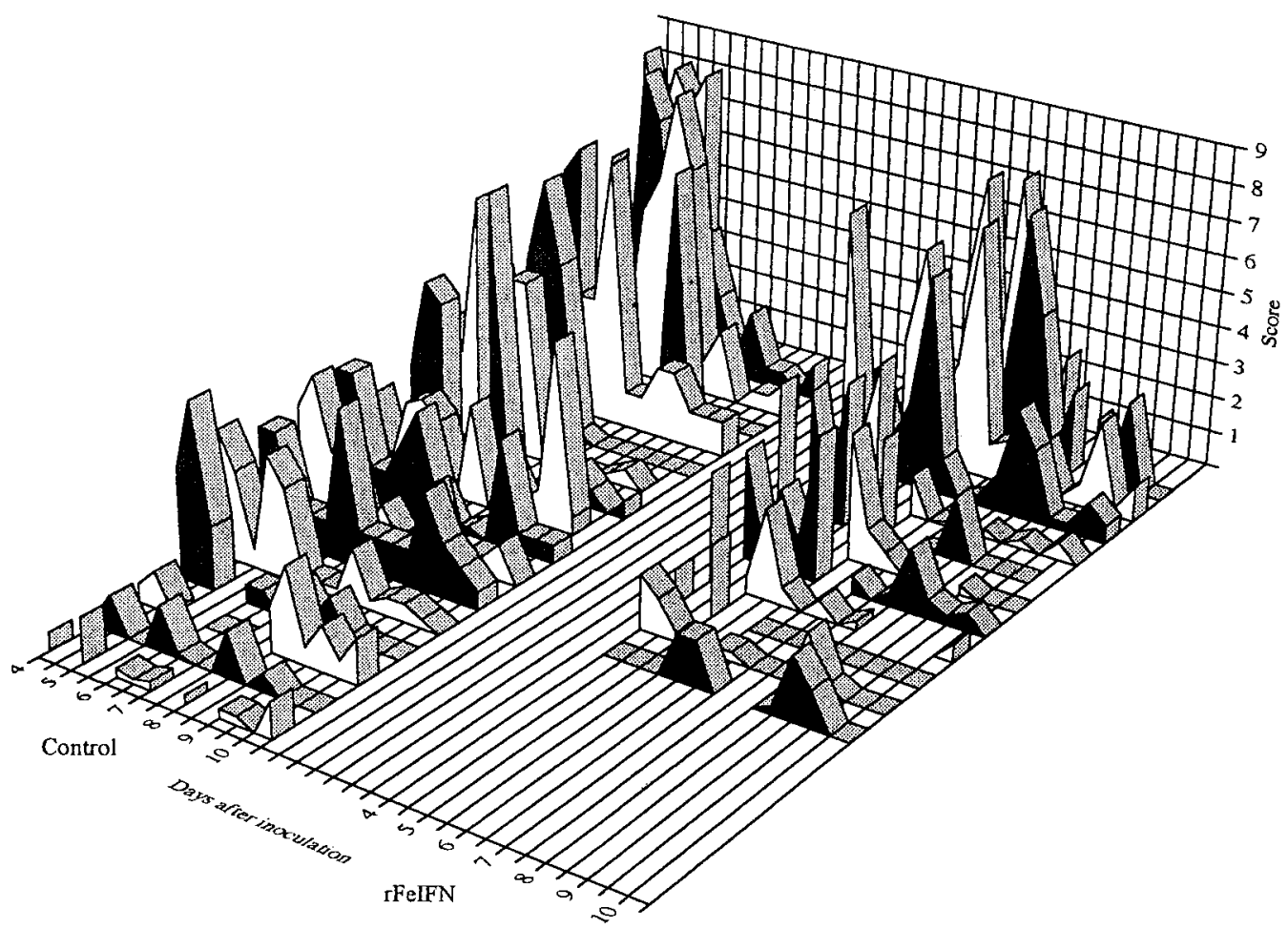

Fig. 3. Scores of fecal conditions of dogs experimentally infected with CPV-22 cc 238 strain. The fecal condition were observed twice a day, in the morning and the evening. Scores were marked according to Table 1 (see Materials and Methods in detail).

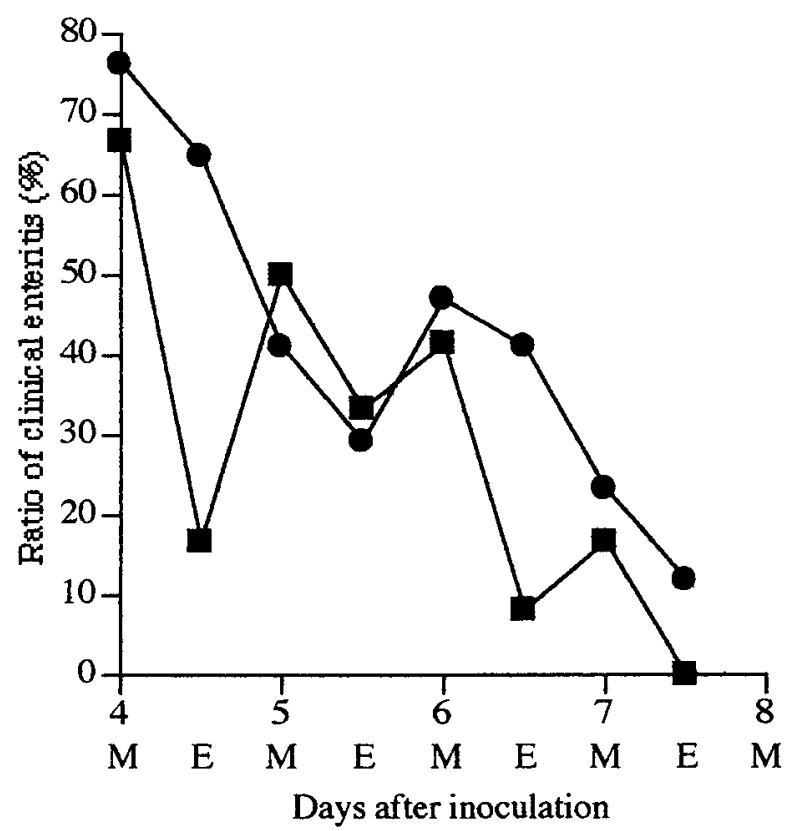

Fig. 4. Ratio of dogs expressing clinical enteritis from day 4 to 7 after virus inoculation. Observations were performed twice a day; in the morning (M) and the evening (E). rFeIFN- $\omega$ was administered on the morning of day 4,5 and 6 . Circles indicate control and squares indicate $\mathrm{rFeIFN}-\omega$ treated groups.

\section{DISCUSSION}

The present study indicates that treatment of beagle dogs with $\mathrm{rFeIFN}-\omega$ ameliorates severe enteritis due to infection with CPV-2 virus. Because IFN activity is highly species specific, several species of IFN genes have been cloned and expressed for veterinary applications [6, 7, 13, 14, 22, 29]. Virus-induced IFN has been produced from canine lymphoid cell cultures [31], while Himmler et al. [7] succeeded in the expression of a canine IFN- $\alpha$ from Escherichia coli that had antiviral activity. However, pure canine IFN preparations are not available for clinical use. Iwata et al. [10] compared the activity of $\mathrm{rFeIFN}-\omega$ with canine IFN by an established biological assay for canine IFN activity. They described a high degree of species specificity between IFNs from cats and dogs. Nevertheless, $\mathrm{rFeIFN}-\omega$ showed growth inhibition activities on 4 different canine tumor-cell lines [30], and a preliminary study demonstrated that in vivo administration of rFeIFN- $\omega$ into dogs resulted in increased production of 2',5'-oligoadenylate synthetase, one of the proteins blocking viral protein synthesis. The effects of rFeIFN- $\omega$ administration against some canine virus infections and tumors was suggested from a number of case reports [32]. Because human IFN- $\omega$ has been reported to have cross-species antiviral and antiproliferative activities $[1,12]$ and it binds to the IFN- $\alpha / \beta$ receptor [4], it was considered likely that rFeIFN- $\omega$ might bind through some 
IFN receptors expressed in dogs.

The death of a control dog expressing a severe hemorrhagic diarrhea suggests that CPV-2 virus exacerbated enteritis and was life-threatening. The data also suggests that one $\mathrm{MU} / \mathrm{kg} / \mathrm{day}$ of $\mathrm{rFeIFN}-\omega$ could switch viral enteritis from serious to a mild form and could be important therapeutically for the exacerbated period of CPV infection. Other clinical symptoms such as vomiting and anorexia were improved by treatment with rFeIFN- $\omega$. The ameliorating effect of rFeIFN- $\omega$ on clinical enteritis in the afternoon following morning administration and the reappearance of enteritis on the next morning suggests a rapid effect and short effective half-life of rFeIFN- $\omega$. This short effective time may account for no differences in fecal condition between the control and the rFeIFN- $\omega$-treated groups from day 8 after virus inoculation. Although one dog treated with $\mathrm{rFeIFN}-\omega$ showed severe vomiting on the morning of day 5, clinical symptoms of this dog were worst at this time. Thus, the vomiting might not be due to the effects of rFeIFN- $\omega$, but to an exacerbated state of the infection.

Both the stimulatory effect on 2',5'-oligoadenylate synthetase in cats [34] and the inhibitory effect on the replication of feline enteropathogenic viruses [19] induced by $\mathrm{rFeIFN}-\omega$ clearly demonstrate the antiviral function of rFeIFN- $\omega$. In the present experiments, rFeIFN- $\omega$ was administered on day 4 after virus inoculation when CPV-2 replication has already spread resulting in cytological effects on germinal epithelium of the intestinal crypts and in the appearance of enteritis $[15,17,18]$. The ameliorating effect

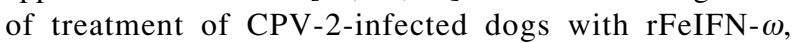
therefore, appears to be due to not only its antiviral activity, but to other functions of IFNs, such as enhancement of immune systems in vivo. It may be of general interest to examine immune responses in rFeIFN- $\omega$-treated dogs under normal conditions and following some other infectious diseases.

Experimental infection of beagle dogs with CPV infrequently results in severe clinical disease like that seen in natural disease [25]. Meunier et al. [18] reported that $10^{5} \mathrm{TCID}_{50}$ of CPV caused clinical signs in about $30 \%$ of infected beagle dogs. In the present experiments, inoculation of $10^{7} \mathrm{TCID}_{50}$ of CPV-2 (cc 238 strain) induce clinical symptoms in all exposed SPF animals, although the severity of symptoms were milder than natural disease. Pollock [25] has shown that giardiasis exacerbates the clinical symptoms of CPV infection. Therefore, the development of severe clinical signs during natural disease may be due to the conditions of maintenance of dogs and exposure to pathogenic cofactor such as internal parasites. Because IFNs are multifunctional, treatment with rFeIFN- $\omega$ may be more effective against natural viral diseases than experimental infections. Thus, we predict that $\mathrm{rFeIFN}-\omega$ treatment of natural CPV infection in dogs will result in greater improvements in clinical treatments.

ACKNOWLEDGEMENTS. We are extremely grateful to Drs. S. Ishiguro, M. Sakamoto and M. Mochizuki, Central
Laboratory, Kyoritsu Shoji Company, for providing the virus and performing the detection of virus DNA in feces and the seroconversion. We wish to thank Dr. J. F. Urban, Jr., IDRL, LPSI, ARS, USDA, Beltsville, U.S.A., for his critical reading of this manuscript. Thanks are also due to Prof. J. Arikawa, Dr. K. Morimatsu and chief technician T. Osanai, Institute for Animal Experimentation, School of Medicine, Hokkaido University, for their useful helps and suggestions.

\section{REFERENCES}

1. Adolf, G. R., Maurer-Fogy, I., Kalsner, I. and Cantell, K. 1990. Purification and characterization of natural human interferon $\omega 1$. Two alternative cleavage sites for the signal peptidase. J. Biol. Chem. 265: 9290-9295.

2. Akiyama, K., Sugii, S. and Hirota, Y. 1993. A clinical trial of recombinant bovine interferon alphal for the control of bovine respiratory disease in calves. J. Vet. Med. Sci. 55: 449-452.

3. Carmichael, L. E., Pollock, R. V. and Joubert, J. C. 1984. Response of puppies to canine-origin parvovirus vaccines. Mod. Vet. Pract. 65: 99-102.

4. Flores, I., Mariano, T. M. and Pestka, S. 1991. Human interferon omega (omega) binds to the alpha/beta receptor. J. Biol. Chem. 266: 19875-19877.

5. Glickman, L. T., Domanski, L. M., Patronek, G. J. and Visintainer, F. 1985. Breed-related risk factors for canine parvovirus enteritis. J. Am. Vet. Med. Assoc. 187: 589-594.

6. Himmler, A., Hauptmann, R., Adolf, G. R. and Swetly, P. 1986. Molecular cloning and expression in E. coli of equine type I interferons. DNA 5: 345-356.

7. Himmler, A., Hauptmann, R., Adolf G. R. and Swetly, P. 1987. Structure and expression in Escherichia coli of canine interferon- $\alpha$ genes. J. Interferon Res. 7: 173-183.

8. Hoofnagle, J. H., Mullen, K. D., Jones, D. B., Rustgi, V., Bisceglie, A. D., Peters, M., Waggoner, J. G., Park, Y. and Jones, E. A. 1986. Treatment of chronic non-A, non-B hepatitis with recombinant human alpha interferon. A preliminary report. New Engl. J. Med. 315: 1575-1578.

9. Isaacs, A. and Lindenmann, J. 1957. Virus interference. I. The interferon. Proc. R. Soc. (Biol.) 147: 258-267.

10. Iwata, A., Mizukoshi Iwata, N., Saito, T., Hamada, K., Sokawa, Y. and Ueda, S. 1996. Cytopathic effect inhibition assay for canine interferon activity. J. Vet. Med. Sci. 58: 2327.

11. Kramer, J. M., Meunier, P. C. and Pollock. R. V. H. 1980. Canine parvovirus: Update. Vet. Med. Small Anim. Clin. 75: $1541-1555$.

12. Kubes, M., Fuchsberger, N. and Kontsek, P. 1994. Crossspecies antiviral and antiproliferative activity of human interferon- $\omega$. J. Interferon Res. 14: 57-59.

13. La Bonnardiere, C., Lefevre, F. and Charley, B. 1994. Interferon response in pigs: molecular and biological aspects. Vet. Immunol. Immunpathol. 43: 29-36.

14. Leung, D. W., Capon, D. J. and Goeddel, D. V. 1984. The structure and bacterial expression of three distinct bovine interferon- $\gamma$ genes. Bio/technology 2: 458-464.

15. Macartney, L., McCandlsh, I. A. P., Thompson, H. and Cornwell, H. J. C. 1984. Canine parvovirus enteritis 2: Pathogenesis. Vet. Rec. 115: 453-460.

16. Marquardt, J., Heymer, J., Heinz, H., Adolf, G. R. and Deegen, E. 1994. Kinetics of inhibition of replication of vesicular 
stomatitis virus in blood mononuclear cells of horses after in vitro and in vivo treatment with recombinant equine interferon- $\beta 1$. Am.J. Vet. Res. 55: 1093-1100.

17. McAdaragh, J. P., Eustis, S. L., Nelson, D. T., Stotz, I. and Kenefick, K. 1982. Experimental infection of conventional dogs with canine parvovirus. Am. J. Vet. Res. 43: 693-696.

18. Meunier, P. C., Cooper, B. J., Appel, M. J. G. and Slauson, D. O. 1985. Pathogenesis of canine parvovirus enteritis: The importance of viremia. Vet. Pathol. 22: 60-71.

19. Mochizuki, M., Nakatani, H. and Yoshida, M. 1994. Inhibitory effects of recombinant feline interferon on the replication of feline enteropathogenic viruses in vitro. Vet. Microbiol. 39: $145-152$.

20. Mochizuki, M., San Gabriel, M. C., Nakatani, H. and Yoshida, M. 1993. Comparison of polymerase chain reaction with virus isolation and haemagglutination assays for the detection of canine parvoviruses in faecal specimens. Res. Vet. Sci. 55: $60-63$.

21. Nagano, Y. and Kojima, Y. 1954. Pouvoir immunisant du virus vaccinal inactive par des rayons ultraviolets. Comp. Rend. Soc. Biol. 148: 1700-1702.

22. Ott, T. L., Van Heeke, G., Johnson, H. M. and Bazer, F. W. 1991. Cloning and expression in Saccharomyces cerevisiae of a synthetic gene for the Type-I trophoblast interferon ovine trophoblast protein-1: Purification and antiviral activity. $J$. Interferon Res. 11: 357-364.

23. Parrish, C. R. 1990. Emergence, natural history, and variation of canine, mink, and feline parvoviruses. Adv. Virus Res. 38: 403-450.

24. Parrish, C. R., O'Connell P. H., Evermann, J. F. and Carmichael, L. E. 1985. Natural variation of canine parvovirus. Science 230: 1046-1048.

25. Pollock. R. V. H. 1982. Experimental canine parvovirus infection in dogs. Cornell Vet. 72: 103-119.
26. Pollock. R. V. H. and Coyne, M. 1993. Canine parvovirus. Vet. Clin. North Ame.: Small Anim. Prac. 23: 555-568.

27. Sakurai, T., Ueda, Y., Sato, M. and Yanai, A. 1992. Feline interferon production in silkworm by recombinant baculovirus. J. Vet. Med. Sci. 54: 563-565.

28. Samuel,C. E. 1991. Antiviral actions of interferon. Interferonregulated cellular proteins and their surprisingly selective antiviral activities. Virology 183: 1-11.

29. Sekellick, M. J., Ferrandino, A. F., Hopkins, D. A. and Marcus, P. I. 1994. Chicken interferon gene: cloning, expression, and analysis. J. Interferon Res. 14: 71-79.

30. Tateyama, S., Priosoeryanto, B. P.,Yamaguchi, R., Uchida, K., Ogiwara, K. and Suchiya, A. 1995. In vitro growth inhibition activities of recombinant feline interferon on all lines derived from canine tumours. Res. Vet. Sci. 59: 275-277.

31. Tsai, S. C. and Appel, M. J. 1983. Virus-induced interferon production in canine lymphoid cell cultures. Am. J. Vet. Res. 44: 1588-1592.

32. Uchino, T. 1997. Review on recombinant feline interferon in Japan. J. Anim. Clin. Med. 5: 1-10 (in Japanese).

33. Ueda, Y., Sakurai, T. and Yanai, A. 1993. Homogeneous production of feline interferon in silkworm by replacing single amino acid code in signal peptide region in recombinant baculovirus and characterization of the product. J. Vet. Med. Sci. 55: 251-258.

34. Ueda, Y., Sakurai, T., Kasama, K., Satoh, Y., Atsumi, K., Hanawa, S., Uchino, T. and Yanai, A. 1993. Pharmacokinetic properties of recombinant feline interferon and its stimulatory effect on 2', 5'-oligoadenylate synthetase activity in the cat. J. Vet. Med. Sci. 55: 1-6.

35. Yamamoto, J. K., Okuda, T. and Yanai, A. 1990. Anti feline herpesvirus and calicivirus effects of feline interferon. J. Interferon Res. 10: S114. 